\title{
The home language environment of monolingual and bilingual children and their language proficiency
}

\author{
ANNA F. SCHEELE and PAUL P. M. LESEMAN \\ Utrecht University
}

AZIZA Y. MAYO

University of London

Received: April 3, 2008 Accepted for publication: March 21, 2009

ADDRESS FOR CORRESPONDENCE

Anna F. Scheele, Utrecht University, P.O. Box 80140, NL-3508 TC Utrecht, The Netherlands.

E-mail: a.f.scheele@uu.nl

\begin{abstract}
This study investigated the relationships between home language learning activities and vocabulary in a sample of monolingual native Dutch $(n=58)$ and bilingual immigrant Moroccan-Dutch $(n=$ 46) and Turkish-Dutch $(n=55)$ 3-year-olds, speaking Tarifit-Berber, a nonscripted language, and Turkish as their first language (L1), respectively. Despite equal domain general cognitive abilities, Dutch children scored higher than the bilingual children on a L1 vocabulary test, and Moroccan-Dutch children had higher second language (L2) vocabulary skills compared to Turkish-Dutch children. Multigroup analyses revealed strong impact on both L1 and L2 skills of language specific input in literate and oral activities. Finally, indications were found of positive cross-language transfer from L1 to $\mathrm{L} 2$ as well as competition between L1 and L2 input.
\end{abstract}

In countries throughout the world, educational achievement of language-minority children from low-income immigrant families consistently falls behind (Stanat $\&$ Christensen, 2006). Disadvantages are already manifest upon introduction to primary school, when these children's first (L1) and second language (L2) skills, in particular vocabulary, are less well developed than the language skills of their monolingual peers (Duursma, Romero-Contreras, Szuber, Proctor, \& Snow, 2007; Leseman, 2000; Leseman \& van Tuijl, 2006; Oller \& Eilers, 2002). Immigrant children are confronted with the difficult task of acquiring a substantial vocabulary in the majority language to succeed in school (Stipek, 2001), while simultaneously having to maintain and expand their L1 skills for all kinds of communicative purposes in the context of the family and wider cultural community. A central question for researchers, educationalists, and policymakers alike, which stills lacks a clear answer, is whether these two tasks are competitive or if they can support each other.

(C) Cambridge University Press 2009 0142-7164/10 \$15.00 
Although language development of monolingual and bilingual children has been widely studied, studies including bilingual children from bilingual low-income immigrant families are scarce. This makes it hard to determine whether the usual contextual factors associated with language development, such as socioeconomic status (SES) of the family and the family's home language and literacy practices (cf. Hoff, 2006), suffice to explain the early language arrears of these children. Findings from studies that included language-minority children suggest that additional factors need to be considered such as the ways in which L1 and L2 input is divided across language interactions at home, the social status of L1, and the access to formal and literate use of L1 (cf. Pearson, 2007).

The current study aims to contribute to the understanding of the processes underlying bilingual immigrant children's educational disadvantages by examining the relationships between their home language environment and their L1 and L2 proficiency. To this purpose we focus on language input patterns within the home context of children from two bilingual immigrant populations and from the majority population in The Netherlands. By detailing language input patterns, rather than using broad measures such as overall percentage of L1 and L2 use (De Houwer, 2007; Gutiérrez-Clellen \& Kreiter, 2003; Oller \& Eilers, 2002), we aim to further clarify the relation between input patterns and language skills. Furthermore, including two immigrant populations that share a similar migration history and socioeconomic background, but strongly differ with regard to the social prestige of their L1s and the access to formal and literate uses these languages provide, will allow us to address the role played by sociohistorical factors at the level of language communities.

\section{HOME LANGUAGE INPUT AND LANGUAGE DEVELOPMENT}

An extensive body of research with monolingual children has established that children's early language skills are strongly related to their experiences with language input in the home context. For instance, there is considerable evidence that SESrelated qualitative and quantitative differences in language learning experiences, or "input," explain variability in children's language skills (Foster, Lambert, AbbottShim, McCarty, \& Franze, 2005; Hoff, 2006; Raviv, Kessenich, \& Morrison, 2004). Overall, children from high SES families by comparison with children from low SES families have more opportunities to experience language input that stimulates language development. For one, they receive more overall language input (Hart \& Risley, 1995). Observational studies indicate that children who receive most language input also receive the kind of language input that is most effective for language learning (Hart \& Risley, 1995; Hoff \& Naigles, 2002). For instance, high SES children more frequently participate in home literacy activities (Bradley \& Corwyn, 2002; Hoff, 2006). Home literacy activities, such as shared book reading and related types of parent-child conversations, are characterized by the use of a rich vocabulary, complex and information-dense sentences, and semantically interconnected discourse, that is, the kind of language use that is generally thought to stimulate language development (Deckner, Adamson, \& Bakeman, 2006; Hoff \& Naigles, 2002; Huttenlocher, Vasilyeva, Cymerman, \& Levine, 2002; Sénéchal \& LeFevre, 2002; Weizman \& Snow, 2001). Furthermore, there is a clear association 
of SES and the occurrence of additional sources of language development, such as watching educational television programs, and overhearing and singing songs (Leseman, Mayo, \& Scheele, 2009; Linebarger \& Walker, 2004; Schön et al., 2008; Wright et al., 2001).

Parents can involve their children in a range of activities that nurture children's language skills. Because these activities generally occur less regularly in low SES families, vocabulary development of children from these families tends to proceed at a slower pace (Hoff, 2006). This appears to be the case for children from low-income immigrant families as well. However, the language input that these children experience is likely to differ even more if they are raised in a bilingual language environment. To date, only a few studies have investigated bilingual children's participation in activities that are associated with language development. These studies show that, as with monolingual children, shared book reading, story telling, conversations, and watching educational television programs positively impact bilingual children's vocabulary and language comprehension, at least in the language used during these interactions (Leseman et al., 2009; Patterson, 2002). Furthermore, studies show that bilingual children's proficiency in each language is strongly related to the amount of input in that language. The more input a child receives in a specific language, the better the child performs on vocabulary, reading, and writing tests in that language (De Houwer, 2007; Duursma et al., 2007; Oller \& Eilers, 2002; Patterson \& Pearson, 2004; Pearson, Fernandez, Lewedeg, \& Oller, 1997). The consistent relationships found between language input through particular language activities at home and children's language development raise an important question. Is there a competition for scarce time resources that affect children's L1 and L2 skills?

\section{POSITIVE AND NEGATIVE EFFECTS OF BILINGUALISM}

Bilingualism as such is reported to come with advantages. It has been noted that bilinguals' combined L1 and L2 vocabulary often exceeds that of monolinguals (Oller, Pearson, \& Cobo-Lewis, 2007; Vermeer, 1992), that the conceptual knowledge basis built up in L1 facilitates learning of L2 (Cummins, 1991; Genesee, Paradis, \& Crago, 2004; Kroll \& de Groot, 2005; Verhoeven, 2007), and that being bilingual brings cognitive advantages such as enhanced metalinguistic awareness and executive control that will also support L2 learning (Bialystok, 2007; Bialystok \& Senmann, 2004). Such a situation of positive bilingualism, marked by transfer of knowledge and skills from L1 to L2, is not limited to bilingualism in favourable socioeconomic, cultural, and political circumstances, or to older students, but is also found with young language-minority children with an immigrant background (Verhoeven, 2007). However, caution is warranted. First, the correlations reported to substantiate positive transfer remain tentative, because both contextual and general cognitive factors may account for the relation, should thus be controlled for. Moreover, if exposure to L1 and L2 is correlated, either positively or negatively, transfer between the languages may be over- or underestimated. Thus, the effects of exposure should be controlled as well.

Second, despite the evidence for positive bilingualism, there is a plausible argument to the contrary, arising from the notion that the quantity of input in either 
language matters, and that L1 and L2 stand in a competitive relation regarding available time for language learning, as was discussed above. If time for language learning is indeed restricted, time spent on learning a new language inevitably takes away time for learning L1. In this sense, acquiring L2, the majority language, will be at the expense of L1, which is defined as a situation of negative, or subtractive, bilingualism (Butler \& Hakuta, 2004; Cummins, 1991). Moreover, also the quality of input matters, which relates strongly to the family's SES, as was discussed above. In the research literature indications can be found that language minority children who grow up in low income families, in societies that provide only limited support for L1 development, if at all, lack sufficiently rich and elaborated language input to develop their L1 skills further (cf. Genesee et al., 2004; Leseman \& van den Boom, 1999; Pearson, 2007). Indeed, the finding in several studies that bilingual immigrant children have a lower proficiency in each language than monolingual peers have in their language (Aarts \& Verhoeven, 1999; Leseman \& van den Boom, 1999; Oller \& Eilers, 2002; Pearson et al., 1997; Patterson \& Pearson, 2004) seems to indicate that subtractive bilingualism might be an issue for these children.

In sum, an important question is if bilingualism in immigrant communities is indeed characterized by contradicting positive and negative mechanisms and how these mechanisms jointly determine child outcomes.

\section{THE CURRENT STUDY}

The main objective of the present study is to gain more insight in the bilingual development of language-minority children with an immigrant background. The study examines the relationships between ethnic-cultural background, SES, home language, and literacy practices, and children's L1 and L2 vocabularies in a sample of Turkish-Dutch, Moroccan-Dutch, and Dutch children and their families. The Moroccans and the Turks are two of the largest non-Western immigrant populations in The Netherlands. Turkish and especially Moroccan families in The Netherlands have a low SES. By comparison with other large bilingual immigrant groups in The Netherlands, Moroccan-Dutch and Turkish-Dutch parents least often address their children in Dutch (Sociaal en Cultureel Planbueau [SCP], 2005). Yet, from age 4, their children, like all 4-year-olds in The Netherlands, are required to participate in the primary school system, where Dutch is the language of instruction. Although Moroccan-Dutch and Turkish-Dutch children are mainly exposed to their L1 before they enter primary school, they are also gradually introduced to Dutch in several ways, for instance, via Dutch television watching, listening to Dutch songs, and input of Dutch by family and community members. We assume that having to acquire two languages in early childhood poses a particular heavy demand for Moroccan-Dutch and Turkish-Dutch children. Because of the low SES of their families, we expect them, overall, to receive less language input through the literate and oral language activities identified in previous research as promoting language development. Moreover, the input they receive needs to be divided over two or more different languages, implying that the amount of input for L1 and especially for L2, separately, will be even less (Paradis \& Genesee, 1995). We hypothesize that reduced input of L1 and L2 provides a likely explanation of the persistent language delays of language-minority immigrant children. 
The expected negative effect of bilingualism, however, may be counteracted, at least partly, by a positive effect of bilingualism that results from the use that bilingual children can make of the knowledge and skills acquired in L1 in learning L2. Given that L1 development in both Moroccan-Dutch and Turkish-Dutch children starts well before they start acquiring Dutch as L2, L1 is assumed to be the more mature language. Therefore, we expect a positive effect of L1 on L2, that partly compensates the negative effect of divided language input.

Concerning possible differences between the two immigrant groups we expect the Turkish-Dutch children to have greater proficiency in their L1, and lower proficiency in their L2 compared to the Moroccan-Dutch children. We expect the Turkish-Dutch children to receive more L1 input, as their parents are reported to maintain their own language to a stronger degree than the Moroccan-Dutch parents (SCP, 2005). Turkish has a relatively high status because of its longstanding literary and academic tradition, and Turkish parents, in principle, can easily access different sorts of official Turkish media, including books and newspapers, to maintain their language (Backus, 2005). Besides Turkish, there will also be exposure to Dutch in Turkish-Dutch families. For the Moroccan-Dutch parents in this study, the situation is quite different. All of them are of Berber descent and they speak a variety of Tarifit-Berber as their L1 (which holds for $70 \%$ of the Moroccan immigrants in The Netherlands; SCP, 2005), in addition to Dutch and, occasionally, Arabic, mainly connected to religious practices. Tarifit is a nonscripted language, not used in education or official public media in Morocco, nor elsewhere (cf. Rosenhouse \& Goral, 2005). Because of these sociohistorical factors, Moroccan-Dutch parents of Berber descent, compared to Turkish-Dutch parents, have less resources available for L1 maintenance and have virtually no access to formal and literate uses of their language. Therefore, we expect them to provide more Dutch as L2 input to their children compared to the Turkish-Dutch parents, which will lead to a higher level of L2 proficiency of the Moroccan-Dutch children.

In sum, we will examine whether children from the different ethnic-cultural groups indeed differ in language input they receive at home and in language skills. We will test the hypothesis that language input in L1 and L2 can explain the relationships found between children's L1 and L2 skills and the family's SES and ethnic-cultural background. Furthermore, we will test the hypothesis that skill in L1 supports acquiring skill in L2. Finally, we will examine differences in language input patterns between the Moroccan-Dutch and Turkish-Dutch participants.

\section{METHOD}

\section{Sample and procedures}

The present study involved 162 3-year-old children from Dutch $(n=58)$, Moroccan-Dutch $(n=46)$, and Turkish-Dutch $(n=55)$ families living in The Netherlands. The respective groups did not differ significantly with regard to children's gender (79 males) or age (range $=35-43$ months, $M=39, S D=1.6$ ). Two large municipalities in The Netherlands provided addresses of Dutch, Moroccan-Dutch, and Turkish-Dutch families with a 3-year-old child. Information on average SES of the neighborhood was used to stratify the sample to 
obtain a representative range in SES. In agreement with demographics in The Netherlands, the immigrant families more often lived in low SES neighborhoods with a high immigrant density than the Dutch families. After selection of target families, parents were sent a letter introducing the study in Dutch and Turkish or Arabic. Families were then personally contacted by a female research assistant with the same cultural background. The research assistant administered a short screening questionnaire in order to exclude single-parent families; children with serious developmental delays or medical speech-hearing problems; children who attended daycare, preschool, or play groups for more than 2 full days or 4 half days per week; and Moroccan-Dutch families who did not speak the TarifitBerber language. Furthermore, as we were interested in immigrant children who were being raised primarily in the language of their cultural community, children who experienced less than $70 \%$ L1 input in the home context were excluded. L1 input in the home context was assessed by asking parents which language they spoke during mealtime, playing, reading, and daily routines. Of the families that met the criteria, $65 \%$ of the Dutch, $66 \%$ Turkish-Dutch, and 44\% MoroccanDutch families agreed to participate. Parents who decided not to participate were either not interested in the study or too busy, or in the case of the immigrant families, objected to home visits. After the data were collected families received a gift voucher of $€ 10$ and a storybook for the child.

Data were collected during two home visits by trained female research assistants (college students majoring in psychology or educational sciences), who belonged to the same cultural community as the family. Each visit took approximately $2.5 \mathrm{hr}$. Following previous studies on effects of the home learning environment, the focus was on the mothers as the primary caregivers of the children. A semistructured questionnaire was administered in personal interviews in the caregiver's language of preference. Fathers were not involved, because we expected that being interviewed by female assistants would be perceived as a violation of cultural and religious customs in the immigrant groups. The alternative, using male research assistants to visit the families, would not have been accepted either. The questionnaire addressed family demographics, language use, and language activities in the home environment. Test assistants were instructed to clarify the questions and to provide concrete examples of what was meant whenever necessary, and they used colourful visual aid cards to support the use of prestructured answering scales. In all cases the test assistants registered the mothers' answers. Standardized tests were administered to the children in a fixed order using laptop computers. Translations of the instruments were provided by Turkish and Tarifit linguists. Moroccan-Dutch assistants were trained to work with a scripted form of the Tarifit language to ensure standardization of the assessments.

\section{Measures}

SES. Family SES was based on two components: the highest completed educational level of both parents ranging from 1 (no education) to 7 (university degree) and the status of their current jobs on the Dutch national job index list ranging from 1 (unemployed) to 6 (scientific job level; Centraal Bureau voor de Statistiek, 2001). SES was computed as the mean of parents educational and job levels $(\alpha=$ .84 for the total sample). 
Table 1. Sample items interview scales

Reading: "How frequently do you read a narrative picture book to your child?"

Storytelling: "How frequently do you tell your child self-made stories, fairy tales, or legends?"

Conversations: "How frequently do you talk with your child about his/her experiences, for instance with which children he/she had played?"

Singing: "How frequently do you and your child sing songs together?"

Educational TV watching: "How frequently does your child watch TV programs that explain things, such as Sesame Street?"

Nonverbal intelligence. Raven's Coloured Progressive Matrices (CPM) was administered to measure children's nonverbal intelligence (Raven, 1995). The Raven CPM consists of 36 perceptual and conceptual matching exercises in which the child has to complete a pattern by choosing one out of six pieces. The test requires minimal verbal instructions, which were given in the children's L1. The test is considered particularly useful for measuring fluid intelligence of children with language difficulties (Carver, 1990) and is viewed as a culturally fair measure of intellectual functioning (Kaplan \& Saccuzzo, 1997). Testing ended when children failed five consecutive items.

Home language environment. Children's experience with language through reading activities and oral language interactions (including television watching) in the family context was determined by a questionnaire based on the Early Childhood version of the HOME observation scheme by Bradley and Caldwell (1984) and previously used questionnaires (e.g., Leseman \& van den Boom, 1999). The HOME EC lists concrete learning activities in the area of motor, cognitive, language, and literacy skills. For the present purpose, the dichotomous scoring of the HOME items was replaced by 5-point Likert scales, with scores ranging from 1 (never) to 5 (daily). Given the focus of the present study, additional items referring to concrete oral and literate language activities were added. The primary caregiver rated how frequently the child participated in these activities. Based on theoretical considerations, and supported by the results of exploratory principal components analysis, five scales, representing five types of literate and oral language activities, were constructed by computing the mean of the items included in these scales (see Table 1 for sample items). The reading scale consisted of eight items and included questions about the frequency of shared reading of narrative stories and information books. The storytelling scale contained four items on the frequency of different kinds of story telling (e.g., true stories, funny stories, tales). The conversations scale was composed of five items, covering different forms of spoken interaction with the child, including conversations about personal experiences, shared memories, and discussions about topics of general interest. The singing scale comprised four items about the frequency of singing or listening to songs and lullabies. Finally, the educational TV scale consisted of two items addressing the frequency of watching TV programs for young children with an educational purpose, like Sesame Street. All scales had satisfactory Cronbach alpha values for the total sample as well as for each subsample separately, ranging from .57 to .90 , 
Scheele et al.: Home language and language proficiency

except for the Cronbach alpha of the conversations scale in the Moroccan-Dutch group, which was .41.

In addition, interviewees were asked to indicate for each type of language activity which language was used, yielding measures of $L 1$ and $L 2$ use for each type of activity separately, with scores ranging from 0 to 1 . Situations in which the target language (L1 or L2) was always used were scored 1. If the target language was mostly used, but another language sometimes, a score of .75 was given. If the target language and another language were used equally, a score of .50 was given. A score of .25 was assigned if another language was used more often than the target language, and finally, a score of 0 was given if the target language was never used with that particular type of activity. Language-specific input measures were constructed by multiplying the five language input measures with the measures of either L1 or L2 use, respectively, with scores ranging from 0 to 5 . Note that, for instance, for Dutch language input a maximum score of 5 meant that the type of language activity concerned was provided very frequently on average (at least once per day) and always only in Dutch (language weight 1 ), whereas a score of 0 would mean that, either the type of activity was never present or the language used was always another language than Dutch. To obtain overall measures of L1 and L2 use in the families, we, in addition, constructed two global scales, ranging from 0 to 1, indicating average L1 use and L2 use across the five types of language activities, weighted by the mean frequencies of the types of activity.

L1 and L2 vocabulary. Children's receptive vocabulary skills were assessed using the receptive vocabulary test of the Diagnostic Test of Bilingualism of the national educational testing service (Verhoeven, Narrain, Extra, Konak, \& Zerrouk, 1995), an instrument specifically developed for research with bilingual immigrant children in The Netherlands (for the construction of equivalent vocabulary measures in Turkish and Berber, respectively, see E-Rramdani, 1999; Verhoeven, 2007). The test required children to match a target word, mentioned by a research assistant, with one out of four pictures. To reduce testing time, the vocabulary test was split in two parts, one part consisting of the odd items and a parallel part consisting of the even items, yielding equivalent parallel forms (the within-language correlation between the two forms was $r=.71, p<.01$ ). In the Moroccan-Dutch and Turkish-Dutch group, the odd-items parallel form of the test was used to assess vocabulary in L1, the other form was used to assess vocabulary in L2. Dutch children were given the second form, Dutch vocabulary, only. Testing continued until the child failed five consecutive items or completed all 30 items of the test. Cronbach alpha values for the receptive vocabulary test ranged from .77 to .89 for the three separate groups.

\section{RESULTS}

\section{Overview of the analyses}

We first present the descriptive statistics of the measurements. Using one-way analysis of variance, we compare the three groups with respect to the family's 
Scheele et al.: Home language and language proficiency

Table 2. Descriptive statistics for observed variables

\begin{tabular}{lcccccc}
\hline & Range & Dutch & Moroccan & Turkish & $F$ & Post Hoc \\
\hline $\begin{array}{l}\text { 1. SES } \\
\text { 2. Raven }\end{array}$ & $1-6.5$ & $4.56(1.2)$ & $2.30(0.80)$ & $3.20(0.95)$ & $65.64 * * *$ & $\mathrm{Du}>\mathrm{Tu}>\mathrm{Mo}$ \\
$\quad$ CPM & $0-36$ & $6.00(2.93)$ & $7.00(3.87)$ & $6.37(2.60)$ & 1.28 & $\mathrm{Du}=\mathrm{Tu}=\mathrm{Mo}$ \\
$\begin{array}{l}\text { 3. Daycare } \\
\text { 4. Siblings }\end{array}$ & $0-4$ & $2.64(1.31)$ & $1.31(1.74)$ & $2.39(1.81)$ & $\begin{array}{l}9.24 * * * \\
\mathrm{Du}, \mathrm{Tu}>\mathrm{Mo}\end{array}$ \\
$\begin{array}{l}\text { 5. Siblings } \\
\text { at school }\end{array}$ & $0-6$ & $0.43(0.68)$ & $1.39(1.54)$ & $0.91(0.87)$ & $10.67 * * *$ & $\mathrm{Du}<\mathrm{Mo}$ \\
$\mathrm{Tu}=\mathrm{Mo}$ & $\mathrm{Tu}>\mathrm{Du}$ \\
\hline \hline
\end{tabular}

Note: SES, socioeconomic status; Du, Dutch sample; Tu, Turkish-Dutch sample; Mo, Moroccan-Dutch sample; Raven CPM, Raven Coloured Progressive matrices (Raven, 1995).

${ }^{a}$ One unit represents 1 day part $(3 \mathrm{hr})$.

$* * p<.01 . * * * p<.001$.

SES, the child's cognitive abilities, the language input through literate and oral language activities at home, and the child's vocabulary. Then we examine the correlations between family SES, language input measures, and vocabulary in the three groups. Finally, we present the results of structural equation modeling (SEM) of the relationships between SES, language input, and vocabulary for the Dutch, Moroccan-Dutch, and Turkish-Dutch subsamples separately.

\section{Descriptives}

Table 2 reports the descriptive statistics. The results reveal strong differences in SES, with the Moroccan-Dutch families, on average, having the lowest SES, because of the low level of education of the parents and the low status of their jobs. Moroccan-Dutch children attended preschool out of home care facilities less frequently than the Turkish-Dutch and Dutch children (mean difference $=3$ $\mathrm{hr} /$ week), receiving less exposure to Dutch as a consequence. Moroccan-Dutch and Turkish-Dutch children did not significantly differ in the total number of siblings or in the number of older siblings attending primary school. The differences between the groups reflect the present demographic characteristics of the Dutch, Moroccan-Dutch, and Turkish-Dutch communities in The Netherlands accurately (SCP, 2005). An important finding is that the three groups did not significantly differ in nonverbal fluid intelligence, measured with the Raven CPM. As will be discussed later, this finding is not coincidental, but replicates the results of other Dutch studies within these ethnic-cultural communities, using different samples.

The findings regarding overall language input and language specific input are presented in Table 3. Recall that language specific input was computed by multiplying the average frequency of literate and oral language activities with the degree of L1 or L2 use during these activities. In addition to this, Figure 1 gives a graphical display of the complex language input patterns in the Moroccan-Dutch and Turkish-Dutch subsamples. First, overall language input through literate and 
Scheele et al.: Home language and language proficiency

Table 3. Descriptive statistics for observed variables

\begin{tabular}{|c|c|c|c|c|c|c|}
\hline & Range & Dutch & Moroccan & Turkish & $F$ & Post Hoc \\
\hline 1. Reading input & $0-5$ & $3.50(0.86)$ & $2.09(1.23)$ & $2.83(1.13)$ & $21.69 * * *$ & $\mathrm{Du}>\mathrm{Tu}>\mathrm{Mo}$ \\
\hline 2. Storytelling & $0-5$ & $2.97(1.07)$ & $2.40(0.86)$ & $2.77(1.22)$ & $3.47 *$ & $\mathrm{Du}, \mathrm{Tu}>\mathrm{Mo}$ \\
\hline 3. Conversations & $0-5$ & $3.15(0.65)$ & $2.49(0.67)$ & $3.01(0.76)$ & $12.38 * * *$ & $\mathrm{Du}, \mathrm{Tu}>\mathrm{Mo}$ \\
\hline 4. Singing & $0-5$ & $3.64(0.77)$ & $1.75(0.83)$ & $2.81(1.00)$ & $60.37 * * *$ & $\mathrm{Du}>\mathrm{Tu}>\mathrm{Mo}$ \\
\hline 5. TV & $0-5$ & $4.29(0.89)$ & 3.47 (1.08) & $3.91(1.24)$ & $7.52 * *$ & $\mathrm{Du}, \mathrm{Tu}>\mathrm{Mo}$ \\
\hline \multicolumn{7}{|c|}{ First Language } \\
\hline 6. Use & $0-1$ & $0.99(0.06)$ & $0.76(0.17)$ & $0.87(0.13)$ & $42.35 * * *$ & $\mathrm{Du}>\mathrm{Tu}>\mathrm{Mo}$ \\
\hline 7. Reading input & $0-5$ & $3.49(0.87)$ & $0.04(0.33)$ & $1.91(1.42)$ & $132.84 * * *$ & $\mathrm{Du}>\mathrm{Tu}>\mathrm{Mo}$ \\
\hline 8. Storytelling & $0-5$ & $2.97(1.07)$ & $1.60(1.34)$ & $2.49(1.25)$ & $16.39 * * *$ & $\mathrm{Du}, \mathrm{Tu}>\mathrm{Mo}$ \\
\hline 9. Conversations & $0-5$ & $3.15(0.65)$ & $2.16(2.78)$ & $2.77(0.78)$ & $25.00 * * *$ & $\mathrm{Du}>\mathrm{Tu}>\mathrm{Mo}$ \\
\hline 10. Singing & $0-5$ & $3.37(0.98)$ & $0.43(0.65)$ & $2.33(1.27)$ & $108.56 * * *$ & $\mathrm{Du}>\mathrm{Tu}>\mathrm{Mo}$ \\
\hline 11. TV & $0-5$ & $4.11(0.92)$ & $0.00(0.00)$ & $1.28(1.38)$ & $234.92 *$ & $\mathrm{Du}>\mathrm{Tu}>\mathrm{Mo}$ \\
\hline 12. Vocabulary & $0-30$ & $16.32(4.83)$ & $11.39(5.57)$ & $10.45(4.75)$ & $21.94 * * *$ & $\mathrm{Du}>\mathrm{Tu}, \mathrm{Mo}$ \\
\hline \multicolumn{7}{|c|}{ Second Language $^{a}$} \\
\hline 13. Use & $0-1$ & & $0.23(0.17)$ & $0.13(0.13)$ & $6.37 *$ & \\
\hline 14. Reading input & $0-5$ & & $1.52(1.58)$ & $0.85(0.79)$ & $29.49 * * *$ & \\
\hline 15. Storytelling & $0-5$ & & $0.54(0.93)$ & $0.28(0.55)$ & $10.95 * *$ & \\
\hline 16. Conversations & $0-5$ & & $0.32(0.49)$ & $0.24(0.49)$ & 0.29 & \\
\hline 17. Singing & $0-5$ & & $0.67(0.76)$ & $0.40(0.55)$ & $7.78 *$ & \\
\hline 18. TV & $0-5$ & & $3.16(1.32)$ & $2.58(1.54)$ & 1.96 & \\
\hline 19. Vocabulary & $0-30$ & & $11.29(4.46)$ & $6.62(4.94)$ & $4.87 * * *$ & \\
\hline
\end{tabular}

Note: Du, Dutch sample; Tu, Turkish-Dutch sample; Mo, Moroccan-Dutch sample.

$a_{n}=101$.

$* p<.05 . * * p<.01 . * * * p<.001$.

oral interactions at home, including television watching, differs strongly between the three groups, regardless the language(s) used with these interactions. Based on the reported mean frequencies, the results indicate that Dutch parents read much more to their children than the Moroccan-Dutch and Turkish-Dutch parents did, whereas the Turkish-Dutch parents provided more of such activities than the Moroccan-Dutch parents did. The differences were rather sizeable (up to 2 standard deviations). Similar results were found for singing. With respect to the other oral language activities, Dutch and Turkish-Dutch parents were found to involve their children equally frequently and both groups of parents did this more frequently than Moroccan-Dutch parents did. Second, use of L1 revealed the expected pattern of differences. Use of Dutch in almost $100 \%$ of the reported settings in the Dutch families is characteristic of the monolingual situation of this group. The only sources that provided Dutch children with input of a different language were singing and television watching (7\% and $4 \%$, respectively). In the Moroccan-Dutch families L1 was used least frequently, as a consequence of the stronger influence of Dutch in these families (see below). Third, the findings for L1 language input through literate and oral interactions in Ll demonstrate the consequences of the need to divide the available time for interaction between the two (or more) languages in a situation of bilingualism. Whereas in the Dutch group the input figures hardly change upon combining the frequency of language 
Scheele et al.: Home language and language proficiency
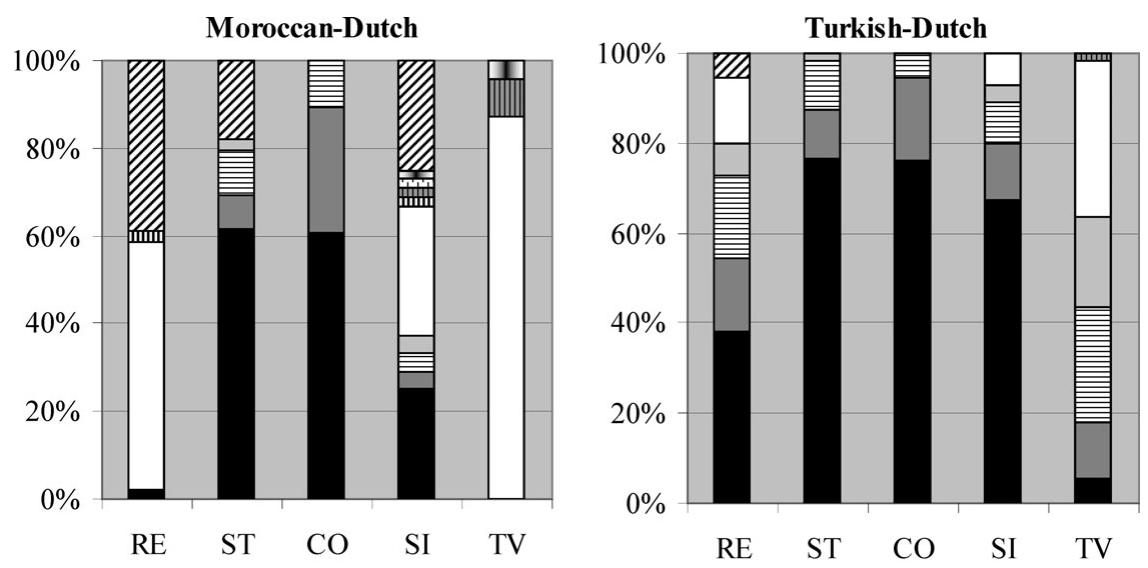

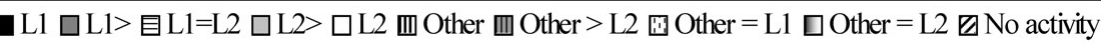

Figure 1. Bilingual parents' language use in oral and literate activities. RE, reading; ST, storytelling; CO, conversations; SI, singing; TV, television viewing.

activities with L1 use, combining the frequency of these activities with L1 use in both immigrant groups results in a profoundly different pattern, especially in the Moroccan-Dutch group, as can be seen in Table 3. For instance, L1 input through shared book reading and television watching is almost absent in the MoroccanDutch group, whereas L1 input through oral interactions varies between $25 \%$ and $87 \%$ of the total language input through these activities. In the Turkish-Dutch group L1 input through reading and oral language activities is also less than the total input through these activities (67\% and $92 \%$, respectively), but the distribution effect generally is less strong than in the Moroccan-Dutch group. Table 3 also shows that L2 input is to a high degree complementary to L1 input, but not fully because of the use of other languages not taken into account in the present study. For instance, in the Turkish-Dutch group L2 input through reading was about $30 \%$ of the total amount of reading interactions, whereas L1 input through reading activities was about $67 \%$; in a few families child book reading did not occur. In the Moroccan-Dutch group the percentages match less exactly because of the use of Moroccan-Arabic and Qu'ran Arabic as additional languages and the fact that in some families the respective activities did not occur (see Figure 1).

Finally, Table 3 shows big differences between the groups in vocabulary scores. The gap found between Moroccan-Dutch and Turkish-Dutch children's vocabulary in Dutch as L2 and Dutch children's vocabulary in Dutch as L1, amounting to almost 1 (Moroccan-Dutch children) to more than 1.5 times the pooled standard deviation (Turkish-Dutch children), was expected given the bilingual background of the Moroccan-Dutch and Turkish-Dutch children. With respect to Dutch as L2, the Moroccan-Dutch children were clearly ahead of the TurkishDutch children. Below we will test whether differences in L2 input can explain the Moroccan-Dutch children's advantage. Most remarkable, however, were the differences found in L1 skills, which were measured with vocabulary tests that 
Scheele et al.: Home language and language proficiency

Table 4. Correlations among the variables in the Dutch subsample $(n=58)$

\begin{tabular}{lccccccc}
\hline \multicolumn{1}{c}{ Variable } & 1 & 2 & 3 & 4 & 5 & 6 & 7 \\
\hline 1. SES & - & $.34^{* *}$ & .13 & $.38^{* *}$ & $.39^{* *}$ & $.35^{* *}$ & $.26^{*}$ \\
2. Reading & & - & $.50^{* * *}$ & $.70^{* * *}$ & $.20 \dagger$ & -.07 & $.41^{* *}$ \\
3. Storytelling & & & - & $.69^{* * *}$ & $.28^{*}$ & -.11 & $.37^{* *}$ \\
4. Conversations & & & & - & $.32^{* *}$ & -.09 & $.59^{* * *}$ \\
5. Singing & & & & & - & $.31^{* *}$ & $.19 \dagger$ \\
6. Educational TV & & & & & - & -.07 \\
7. Vocabulary & & & & & & - \\
\hline \hline
\end{tabular}

Note: SES, socioeconomic status.

$\dagger p<.10 .{ }^{*} p<.05 . * * p<.01 . * * * p<.001$.

were constructed as equivalent parallel tests across the languages. The results indicate that the Moroccan-Dutch and Turkish-Dutch children were not only behind in Dutch as L2 but also rather strongly in L1 vocabulary relative to their Dutch monolingual peers. Considering L1 vocabulary, the gap for the MoroccanDutch children was about 0.9 times the pooled standard deviation and for the Turkish-Dutch children almost 1.

Preliminary analyses. The variables included in the correlation analysis and SEM models were checked for outliers and missing data. No extreme outliers were found when looking at the variables within each group separately. To check for outliers between predictor and outcome variables, regression analyses were conducted. Outliers greater than 2 standard deviations were excluded by replacing the respective value by a missing value (Dutch 3.4\%, Moroccan-Dutch 2.2\% for L1 and 2.2\% for L2, Turkish-Dutch 3.6\% for L2). Two variables suffered from missing values: L1 receptive vocabulary (2.2\% Moroccan-Dutch) and L2 receptive vocabulary (2.2\% Moroccan-Dutch, 5.5\% Turkish-Dutch), primarily caused by children's refusal to cooperate on these tests. To address the missing data problem, and to avoid biased results and sample size reduction in case of listwise deletion (Enders, 2001), the missing data were imputed using the regression method.

\section{Correlational analysis}

To examine the role of input, structural equations, "path," modeling (SEM) with Amos was used, separately for the Dutch and the Moroccan-Dutch and TurkishDutch groups. Before presenting the results, we will briefly review the intercorrelations of SES, oral and literate language activities at home, and children's vocabulary skills within each group. Nonverbal intelligence was not included because preliminary analyses revealed no significant correlations with children's receptive vocabulary scores. Table 4 presents the results for the Dutch group. As was expected, the L1 input measures correlated significantly with SES, except for storytelling. Furthermore, frequency of reading, storytelling and conversations correlated moderately to strongly with children's receptive vocabulary. Educational television watching and singing were not related to children's vocabulary, 
Scheele et al.: Home language and language proficiency

Table 5. L1 input: Correlations among the variables in the bilingual subsamples

\begin{tabular}{|c|c|c|c|c|c|c|c|c|}
\hline Variable & 1 & 2 & 3 & 4 & 5 & 6 & 7 & 8 \\
\hline \multicolumn{9}{|c|}{ Moroccan $(n=46)$} \\
\hline 1. SES & - & - & -.01 & -.09 & $-.21 \dagger$ & - & .02 & .14 \\
\hline 2. Reading L1 & & & - & - & - & - & - & - \\
\hline 3. Storytelling L1 & & & - & $.66^{* * *}$ & $.31 *$ & - & $.41 * *$ & .06 \\
\hline 4. Conversations L1 & & & & - & $.37 * *$ & - & $.39 * *$ & -.06 \\
\hline 5. Singing L1 & & & & & - & - & .06 & -.08 \\
\hline 6. Educational TV L1 & & & & & & - & - & - \\
\hline 7. Vocabulary L1 & & & & & & & - & $.30 *$ \\
\hline 8. Vocabulary L2 & & & & & & & & - \\
\hline \multicolumn{9}{|c|}{ Turkish $(n=55)$} \\
\hline 1. SES & - & -.15 & -.04 & -.02 & .12 & -.04 & -.05 & .00 \\
\hline 2. Reading L1 & & - & $.56 * * *$ & $.57 * * *$ & $.25 \dagger$ & .14 & .06 & .15 \\
\hline 3. Storytelling L1 & & & - & $.72 * * *$ & $.28 *$ & .13 & $.33 * *$ & .02 \\
\hline 4. Conversations L1 & & & & - & $.21 \dagger$ & .06 & $.45^{* * *}$ & $.25 *$ \\
\hline 5. Singing L1 & & & & & - & .13 & .00 & $-.30 *$ \\
\hline 6. Educational TV L1 & & & & & & - & -.19 & .02 \\
\hline 7. Vocabulary L1 & & & & & & & - & $.19 \dagger$ \\
\hline 8. Vocabulary L2 & & & & & & & & - \\
\hline
\end{tabular}

Note: L1, first language; SES, socioeconomic status, L2, second language; In the Moroccan subsample, intercorrelations of reading L1 and TV L1 are not reported, because only one Moroccan parent indicated reading in Berber (through an online translation of a book) and Berber television did not exist.

$\dagger p<.10 . * p<.05 . * * p<.01 . * * * p<.001$.

and therefore not included in the SEM analysis to be reported below. Tables 5 and 6 list the correlations of the L1 and L2 variables for the Moroccan-Dutch and Turkish-Dutch group, respectively. Recall that language-specific input in these groups was indicated by the variables that combined the reported frequency of the language activities with the language that was used in these activities. The results reveal a difference with the Dutch group regarding the commonly found association between SES and language input. Contrary to the findings in the Dutch group, SES did not significantly relate to any of the L1 input measures in both immigrant groups. Furthermore, in the Turkish-Dutch group, SES was also unrelated to the L2 input measures.

Of particular interest for the present study are the correlations between the L1 and L2 oral and literate language activities provided at home and MoroccanDutch and Turkish-Dutch children's L1 and L2 vocabulary. Tables 4 and 5 show that, as in the Dutch group, language input indeed correlated with language outcomes in these groups. However, the patterns of correlations differed across the groups. As in the Dutch group, frequency of L1 storytelling and conversations related to Moroccan-Dutch and Turkish-Dutch children's L1 vocabulary, whereas 
Scheele et al.: Home language and language proficiency

Table 6. L2 input: Correlations among the variables in the bilingual subsamples

\begin{tabular}{|c|c|c|c|c|c|c|c|c|}
\hline Variable & 1 & 2 & 3 & 4 & 5 & 6 & 7 & 8 \\
\hline \multicolumn{9}{|c|}{ Moroccan $(n=46)$} \\
\hline 1. SES & - & $.44 * *$ & $.40 * *$ & $.46^{* *}$ & $.58 * * *$ & -.18 & .02 & .14 \\
\hline 2. Reading L2 & & - & $.50 * *$ & $.64 * * *$ & $.46^{*}$ & .21 & -.17 & .17 \\
\hline 3. Storytelling L2 & & & - & $.62 * * *$ & $.56 * * *$ & -.16 & -.16 & -.07 \\
\hline 4. Conversations L2 & & & & - & $.48 * * *$ & -.10 & -.11 & $.23 \dagger$ \\
\hline 5. Singing L2 & & & & & - & .02 & .00 & $.34^{*}$ \\
\hline 6. Educational TV L2 & & & & & & - & -.15 & .10 \\
\hline 7. Vocabulary L1 & & & & & & & - & $.30 *$ \\
\hline 8. Vocabulary L2 & & & & & & & & - \\
\hline \multicolumn{9}{|c|}{ Turkish $(n=55)$} \\
\hline 1. SES & - & -.12 & -.05 & -.05 & -.05 & -.13 & -.05 & .00 \\
\hline 2. Reading L2 & & - & $.36^{* *}$ & $.36^{* *}$ & $.40 * *$ & .04 & .00 & .14 \\
\hline 3. Storytelling L2 & & & - & $.82 * * *$ & $.47 * * *$ & .04 & .01 & $.40 * * *$ \\
\hline 4. Conversations L2 & & & & - & $.59 * * *$ & .02 & -.04 & $.27^{*}$ \\
\hline 5. Singing L2 & & & & & - & $.19 \dagger$ & -.07 & $.42 * *$ \\
\hline 6. Educational TV L2 & & & & & & - & -.15 & .09 \\
\hline 7. Vocabulary L1 & & & & & & & - & $.19 \dagger$ \\
\hline 8. Vocabulary L2 & & & & & & & & - \\
\hline
\end{tabular}

Note: L2, second language; SES, socioeconomic status; L1, first language. $\dagger p<.10 . * p<.05 . * * p<.01 . * * p<.001$.

frequency of L1 singing and educational TV watching did not. In contrast with the Dutch group, language input through reading in either L1 or L2 was not related to the Moroccan-Dutch and Turkish-Dutch children's L1 and L2 vocabulary. Another difference with the Dutch group was that singing in L2 did relate to Moroccan-Dutch and Turkish-Dutch children's L2 vocabulary. Furthermore, storytelling in L2 seemed less important as a source of language input in the Moroccan-Dutch group, probably because of the low frequency of story telling and the low degree of use of Dutch with this particular type of language activity (see Table 3 and Figure 1).

Another point of interest for the present study is the correlation between the L1 and L2 vocabularies of the Moroccan-Dutch and Turkish-Dutch children, which may point to transfer of knowledge from L1 to L2. As expected, Table 4 indeed shows a significant correlation of L1 vocabulary with L2 vocabulary for the Moroccan group $(r=.30, p<.05)$ and a small, borderline significant correlation for the Turkish group $(r=.19, p<.10)$.

\section{SEM}

Dutch sample. To examine the effect of Dutch language (L1) input on vocabulary in the Dutch group, a path model was specified with one latent factor representing L1 input, indicated by the measured constructs reading, storytelling, and conversations. The observed variable Dutch receptive vocabulary was the dependent. L1 
input was included as endogenous variable and presupposed to mediate, at least partly, the effect of SES on vocabulary. In addition to the chi-square goodness of fit test, the comparative fit index (CFI), the root mean square error of approximation (RMSEA), and the Tucker-Lewis coefficient (TLI) were used to evaluate the model fit. Fit was considered to be satisfactory when the chi-square statistic was not significant at $p<.05$, CFI $>.90$, RMSEA $<.08$, and TLI $<.09$ (Hu \& Bentler, 1998).

The SEM analysis comprised two steps. In the first step an initial path model was tested, including both direct and indirect effect of SES on receptive vocabulary. The initial model fitted the data well, $\chi^{2}(11)=3.38, p>.05$; CFI $=1.000$; $\mathrm{RMSEA}=0.000 ; \mathrm{TLI}=1.015$. However, the direct path from SES to vocabulary, assessed by $z$ tests of the ratio of parameter coefficients to their robust standard estimates, was not significant $(\beta=.06, p>.05)$. Therefore, in the second step, the direct path was removed from the model to yield a more parsimonious model with fewer estimated parameters. Although the model fit did not significantly improve, $\Delta \chi^{2}(1)=0.23, p>.05$, the final model with full mediation of the SES effect on vocabulary fitted the data very well, $\chi^{2}(10)=3.62, p>.05$; CFI $=1.000$; RMSEA $=0.000$; TLI $=1.027$, and was more parsimonious. The final model is presented in Figure 2. The model shows a strong effect of language input on vocabulary $(\beta=.70, p<.001)$. Furthermore, the effect of SES on L1 vocabulary was fully mediated by L1 input.

Moroccan-Dutch and Turkish-Dutch samples. To simultaneously examine the effect of L1 and L2 input on L1 and L2 vocabulary in the Moroccan-Dutch and Turkish-Dutch group, a similar modeling approach was followed as before, but now with two latent factors, for L1 and L2 input, respectively. Furthermore, a few adaptations were made based on the correlation analysis. First, reading activities in L1 and L2 were not included as measured constructs of the latent input factors, because they were correlated with neither L1 nor L2 vocabulary in the Moroccan-Dutch and Turkish-Dutch groups. Second, there were significant correlations between L2 singing and L2 vocabulary in both immigrant groups. Therefore, L2 singing was added as an additional indicator of the latent factor L2 input. Third, to allow multigroup comparison of the effects of L2 input with comparable input measures and equal measurement weights across groups, L2 storytelling was not included in the model, because this type of language activity appeared to be relevant in the Turkish-Dutch group only.

Two further adjustments concerned the core hypotheses of the present study. First, to test the transfer hypothesis, a path was specified from L1 vocabulary to L2 vocabulary. Second, to test the competition hypothesis, a bidirectional correlation was specified between L1 input and L2 input, expecting a negative value. The multigroup option was used to examine whether L1 ands L2 input effects on L1 and L2 vocabulary, and the effects of SES were similar in the Moroccan-Dutch and Turkish-Dutch groups.

The initial model again postulated direct effects of SES on L1 and L2 input, and direct and indirect effects of SES on L1 and L2 vocabulary via L1 and L2 input. Model testing proceeded in six steps. In the first step, the two groups were constrained to be similar on every parameter except for intercept means and 


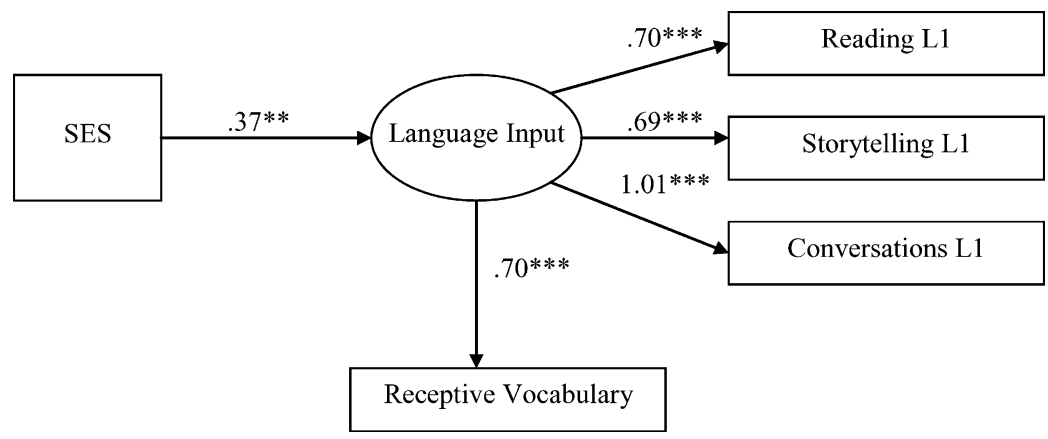

Figure 2. Structural model on the relations between socioeconomic status (SES) and monolingual children's first language (L1) vocabulary skills. $* * p<.01 . * * p<.001$.

random error components. Second, as the correlation analysis indicated that the correlations between SES and L1 input measures were close to zero in the TurkishDutch as well as the Moroccan-Dutch group, we examined whether the path from SES to L1 input could be removed from the model. The path was not significant ( $\beta=-.03, p>.05)$, and, therefore, removed. Removing the path did not lead to a significantly worse model fit, $\Delta \chi^{2}(1)=0.11, p>.05$. Furthermore, the direct effects of SES on L1 and L2 vocabulary were close to zero, and therefore removed as in the Dutch sample. Third, we used critical ratio comparisons to identify which model parameters significantly differed between the groups. The results indicated significant differences between the two groups in the variance of SES $(Z=-5.17, p<.0001)$, in the error covariance between singing in L2 and storytelling in L2 $(Z=2.27, p<.05)$, and in the effect of SES on L2 input ( $Z$ $=4.24, p<.0001)$. In the next analysis steps, these parameters were therefore set free to vary between the groups, leading to significantly better model fits, $\Delta \chi^{2}(1)=191.49, p=0 ; \Delta \chi^{2}(1)=12.69, p=0$ and $\Delta \chi^{2}(1)=18.05, p=$ 0 . Fourth, model testing indicated that the effect of SES on L2 Input was not significant in the Turkish-Dutch group $(\beta=.00, p>.05)$. Therefore, the effect was fixed to zero in the Turkish-Dutch group. The resulting more parsimonious model did not fit worse to the data, $\Delta \chi^{2}(1)=.28, p>.05$. Fifth, we tested whether in the Moroccan-Dutch group the effect of SES on L2 vocabulary was fully mediated by L2 input. The direct path between SES and L2 vocabulary was close to zero and statistically not significant $(\beta=.00, p>.05)$, indicating that L2 input fully mediated the effect of SES on L2 vocabulary in the MoroccanDutch group. In the Turkish-Dutch group SES was not related to L1 input or to L2 input. Therefore, mediation was not further examined in this group. Finally, the measurement weights were released to control for measurement invariance between groups. Allowing the measurement weights to vary between the two groups did not significantly improve model fit, $\Delta \chi^{2}(2)=.43, p>.05$, indicating that the input measurements were equivalent in both groups which is a prerequisite for cross-group comparisons.

The final model for the multigroup, presented in Figure 3, fitted the data well, $\chi^{2}$ $(36)=39.36, p>.05 ; \mathrm{CFI}=0.988 ; \mathrm{TLI}=0.981 ; \mathrm{RMSEA}=0.031$. The model 
Moroccan-Dutch

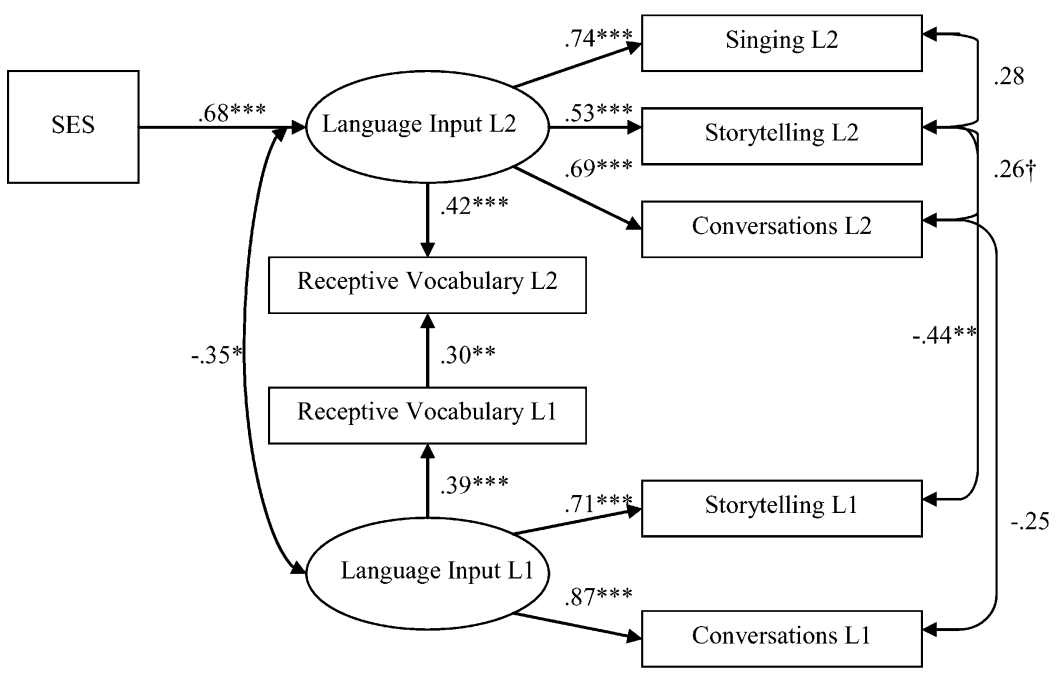

Turkish-Dutch

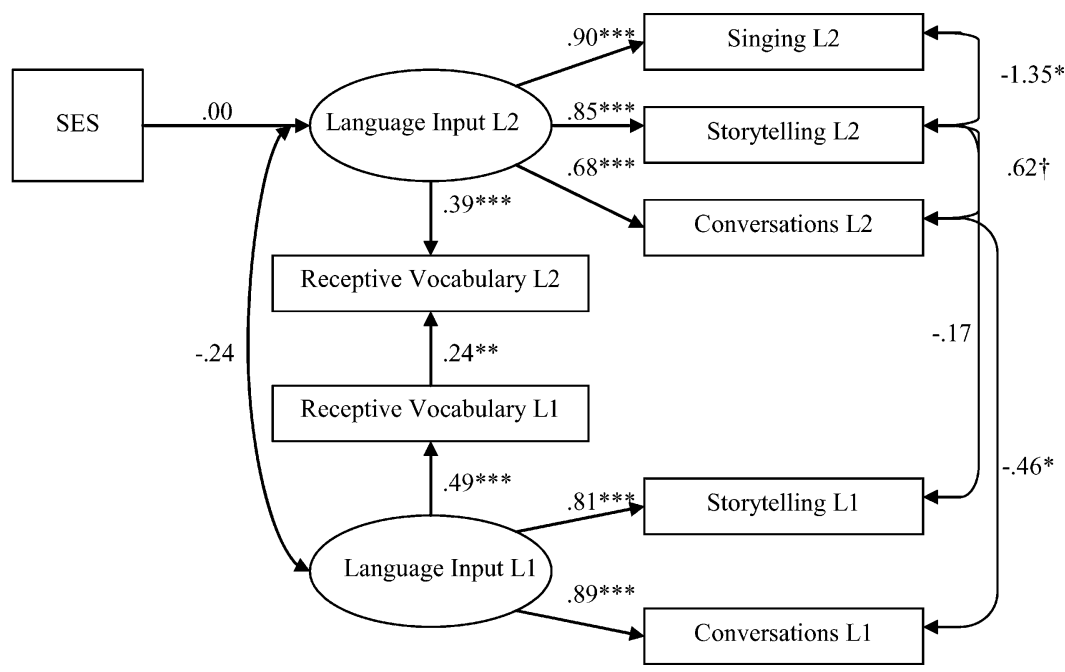

Figure 3. A structural model on the relations between socioeconomic status (SES) and bilingual children's first language (L1) and second language (L2) vocabulary skills. ${ }^{* *} p<.01$. ***p $<$ .001 .

shows moderately strong effects of $\mathrm{L} 1$ input on $\mathrm{L} 1$ vocabulary $(\beta=.49, p<.001$ for the Turkish-Dutch group; $\beta=.39, p<.001$ for the Moroccan-Dutch group), and a moderately strong effect of L2 input on L2 vocabulary $(\beta=.39, p<.001$ for the Turkish-Dutch group; $\beta=.42, p<.001$ for the Moroccan-Dutch group). In the Moroccan-Dutch group, the effect of SES on L2 skill was fully mediated by 
Scheele et al.: Home language and language proficiency

L2 input; SES was not related to L1 input or L1 vocabulary. In the Turkish-Dutch group, SES was unrelated to input and vocabulary in both L1 and L2. Two paths are of special interest. First, there was a statistically significant effect of L1 on L2 vocabulary $(\beta=.24, p<.10$ for the Turkish-Dutch; $\beta=.30, p<.01$ for the Moroccan-Dutch group), indicating positive transfer from L1 vocabulary to L2 vocabulary. Second, there were negative correlations between L1 input and L2 input, reflecting competition between the languages $(\beta=-.24, p>.05$ for the Turkish-Dutch; $\beta=-.35, p<.05$ for the Moroccan-Dutch group). Note that the effect sizes of transfer and competition are roughly similar.

\section{DISCUSSION}

The aim of the present study was to examine whether the commonly found language disadvantages of low income bilingual immigrant children could be explained by the patterns of L1 and L2 input in the children's home environment. Using parallel language tests of receptive vocabulary that were specifically constructed for research into bilingual development, the bilingual Moroccan-Dutch and Turkish-Dutch immigrant children in the present sample were found to be less proficient in both L1 and L2 compared to monolingual native Dutch children. As was expected, the differences in L1 and L2 skills were related to L1 and L2 input at home. Based on reports by the principal caregiver, we found profound differences in the amount of language learning activities at home. Overall, the MoroccanDutch and Turkish-Dutch children received less L1 and L2 input through shared book reading and through a range of oral language interactions, including activities such as personal conversations and oral story telling. The finding that language input through oral interactions related to children's language outcomes is an important addition to Patterson (2002), who found that book reading activities can stimulate bilingual children's L1 and L2 development.

An important finding of the present study was that the bilingual immigrant children equalled the Dutch monolingual children in nonverbal intelligence. In a related study of our lab with a different sample of native Dutch and Turkish-Dutch 4-year-olds, using more extensive measures of nonverbal intelligence, digit span, and visuospatial working memory (Messer, Leseman, Boom, \& Mayo, in press), essentially the same result was found. Taken together, these findings provide support for the hypothesis that the language disadvantages of bilingual immigrant children cannot be attributed to their general learning capacity, but likely stem from differences in language input. The results clearly demonstrated that being raised in bilingual immigrant families substantially impacted the L1 and L2 input children received: as the input was divided over two languages, minority-language children experienced far less literate and oral interactions compared to native monolingual children.

By testing separate SEM models for the three groups, we tried to further clarify the ways in which being raised in a particular cultural and linguistic community influences young children's language development. The first model involved the Dutch group and focused on determinants of Dutch vocabulary. The results indicated that the effect of SES on vocabulary was entirely mediated by the effect of L1 language input. Moreover, the effect of language input on vocabulary was 
rather strong $(\beta=.70, p<.001)$, confirming the hypothesis that reading, storytelling, and conversations positively related to Dutch children's vocabulary. The second SEM-model involved the Moroccan-Dutch and Turkish-Dutch children and focused on their L1 and L2 receptive vocabulary, measured with equivalent parallel tests. The results again supported the input hypothesis, although the effects of input were less strong than in the model of the Dutch group $(\beta \mathrm{s}=.39-.42$, $p<.001)$. Furthermore, L1 input was not significantly related to SES, whereas L2 input almost completely mediated the effect on L2 of SES differences within the Moroccan-Dutch sample, but not in the Turkish-Dutch sample.

The role of the family's SES as a background characteristic that is associated with the amount and quality of language input to children, and through language input with children's language development, is widely documented in previous research (i.e., see, Foster et al., 2005; Hart \& Risley, 1995; Hoff, 2006; Leseman \& van den Boom, 1999; Leseman \& van Tuijl, 2006; Raviv et al., 2004). SES usually refers to parents' formal education, the degree of symbolic content of their jobs, and the availability of economic and cultural resources that all are considered to directly or indirectly influence children's language development. Therefore, the present findings regarding the role of SES deserves further consideration. First, it should be noted that the vast majority of studies showing SES effects on language development were conducted in monolingual samples. Second, the few studies that included low SES bilingual immigrant families, as in the present study, typically provide less clear-cut results on the role of SES (Duursma et al., 2007; Leseman \& van den Boom, 1999; Oller \& Eilers, 2002). The present results for the Dutch group corroborate previous research, that is, SES was significantly and positively associated with the amount of L1 language input through both literate and oral interactions in the family $(\beta=.37, p<.01)$. However, the findings for the Moroccan-Dutch and Turkish-Dutch groups show a more complicated pattern. In both groups, the effects of SES on L1 input were close to zero and statistically not significant. In the Moroccan-Dutch group SES had a statistically significant positive effect on L2 language input $(\beta=.68, p<.001)$, but in the Turkish-Dutch group SES had no effect at all.

There are several possible explanations for these findings. Restriction of range could underlie the absence of clear relationships of SES and language input. However, Levine's test for equality of variance in SES across groups revealed that the groups did not significantly differ in SES variance, except for the MoroccanDutch and Dutch group (Field, 2005). Moreover, note that a significant effect of SES on L2 input was found for the Moroccan-Dutch group. Furthermore, the groups did not significantly differ in the variances of the language input measures. An alternative explanation might be found in the patterns of language use. The pattern of L1 and L2 use, and consequently, L1 and L2 input in the two immigrant groups, differed in a number of respects, related to the respective language status. As expected, the amount of L2 input through oral language interaction was bigger in the Moroccan-Dutch group than in the Turkish-Dutch group. Reversely, the amount of L1 input through both literate and oral language interactions was bigger in the Turkish-Dutch group. The lack of opportunities for Moroccan-Dutch families to use their L1 in formal and literate ways explains the strong association of L2 input and SES. The higher educated who, as a consequence of their status, are 
inclined to provide more formal, in particular literate, language activities to their child, have no other option than to take recourse to (written materials in) Dutch language. In addition, being higher educated in the Moroccan-Dutch community often means that, after migration at a young age, at least part of the school career was completed in The Netherlands. Public primary and secondary education in the country of origin, Morocco, is still limited in the rural areas where most of the Moroccan immigrants in The Netherlands were born, and especially difficult to access for women. Finally, is has been observed that, because of absence of formal use of Tarifit-Berber in education, public administration, and public media, L1 loss is stronger among the higher educated Moroccan-Dutch immigrants than among the higher educated in other language minority groups, such as the Turks (Backus, 2005).

The situation of the Turkish-Dutch groups differs in several respects. Because of a more extensive education system, increasingly also in rural areas, many Turks in The Netherlands have completed primary education and often a few years of secondary education as well in Turkey. Moreover, language maintenance is considered to be especially important in the Turkish immigrant community (Backus, 2005). Language maintenance, moreover, is strongly supported by accessible sources of formal and academic Turkish language, including public Turkish television on the Dutch cable, newspapers, books, and picture books for young children. Therefore, socioeconomic differences between Turkish-Dutch families, do not necessarily run parallel to differences in experience with Dutch as L2 and with language choice at home, at least less strongly so than in the Moroccan-Dutch group, explaining the lack of association between SES and both the L1 and L2 input measures.

In this respect, it is interesting to note that the more intensive exposure to L1 did not lead to a significant advantage in L1 vocabulary for the Turkish-Dutch children in this study compared to the Moroccan-Dutch children. However, the higher level of L2 input in the Moroccan-Dutch families did lead to a clear advantage in L2 vocabulary for the Moroccan-Dutch children compared to the Turkish-Dutch children. A possible explanation is that the need to divide the available family interaction time over two languages, resulted also in the TurkishDutch families in this study in too low intensity of L1 input, especially with respect to language learning activities that propel L1 learning beyond a basic level of everyday communication (cf. Pearson, 2007). For instance, although much more than the Moroccan-Dutch families, still only $40 \%$ of the Turkish families reported to read to their children in L1. Therefore, a related explanation might be that, given the lack of a positive association with SES discussed above, the quality of L1 input was not sufficient to stimulate L1 development beyond the basic level of the lexical and grammatical knowledge for informal, everyday interpersonal communication, which was reflected in low scores on the vocabulary test in Turkish (for a further discussion of the threshold hypothesis implied here, see Leseman et al., 2009). Thus, although Turkish-Dutch parents in principle had more written and oral Turkish language resources at their disposal to provide high quality L1 input compared to Moroccan-Dutch parents, the overall low education levels of the Turkish-Dutch parents in this sample probably set limits to the use of these resources, thereby limiting the linguistic quality of the L1 
input in these families. Indeed, in two previous observation studies parent-child interactions in Turkish-Dutch families with young children, using L1 in reading and problem-solving tasks, were found to be less cognitively demanding than similar interactions in Dutch and Surinamese-Dutch families (Leseman \& van den Boom, 1999; Leseman \& van Tuijl, 2006).

The results of the present study provided support for both the competition hypothesis and the positive transfer hypothesis, suggesting that both mechanisms are present in situations of bilingual upbringing. The results of the SEM analysis revealed that the effect sizes of the two mechanisms were roughly similar, suggesting a balance between negative and positive effects of bilingualism. It should be noted, however, that the small positive transfer effects found in this study $(\beta=.24, p<$ .01 for the Turkish-Dutch; $\beta=.30, p<.01$ for the Moroccan-Dutch group), replicating the results of Verhoeven (2007), may also be partly because of cognitive and verbal abilities of the children, so that the negative effects of bilingualism (competition) still outweigh the positive effects (transfer). Furthermore, presumably because of the relatively low level of L1 input, immigrant children's actual level of L1 vocabulary was below the age norms. Nonetheless, insofar the L1 vocabulary test can be seen as representing broader lexical, semantic, grammatical, and metalinguistic knowledge of L1, the present results support the hypothesis that young L2 learners can use their L1 knowledge in this broad sense to learn L2, even if acquisition of L1 is only a few years ahead of the acquisition of L2, as in the present sample.

\section{CONCLUSIONS AND LIMITATIONS}

To conclude, we will summarize the most important findings and discuss some of the limitations of the present study. Moroccan-Dutch and Turkish-Dutch 3-yearolds did not differ from native Dutch peers in basic cognitive ability involved in learning language from input. The differences in the patterns of language input found between the three groups largely explained the differences in children's L1 proficiency, and, in the Moroccan-Dutch and Turkish-Dutch group, the differences in children's L2 vocabulary. Furthermore, the differences in input patterns were clearly related to background characteristics, including the status of the minority languages involved. In view of optimal preparation for primary school, being raised in a low-SES bilingual immigrant family puts young children's language development at a double risk: first, the (limited) available time for literate and oral language interactions has to be divided over two languages, which have to compete for scarce resources; second, the lack of association of SES with L1 input limits the support of L1 for acquiring L2. Nonetheless, even 3-year-old bilingual children apparently could use their skill in L1 to learn L2 to some extent. However, it remains to be seen whether the transfer of L1 to L2 will hold with increasing age.

The study suffered from a number of limitations. First, the measures of language input were based on primary caregivers' self-reports in personal interviews with semistructured questionnaires. Answers may have been biased because of social desirability tendencies and to inaccuracies in rating the frequencies of particular language interactions at home. Moreover, the data did not allow us to draw firm 
Scheele et al.: Home language and language proficiency

conclusions about the quality of the language interactions at home. Observational measures of both the quantity and quality of the language input are needed to deepen understanding of the role of input in (bilingual) language development. Second, the present study focused only on parent-related language input. It is recommendable to include also language input provided by peers, daycare teachers, and older siblings. Third, the present study was not longitudinal. To provide for a stronger basis for causal inferences, a longitudinal design is needed. In addition, L1 and L2 language development was in the present study measured only by vocabulary, seen as proxy for broader lexical, grammatical, and discursive skills. Clearly, broader assessment of bilingual children's L1 and L2 development will contribute to further understanding of the phenomena reported in this article. Despite the limitations, the present study has provided useful insights in the language input patterns in mono- and bilingual families as related to children's language skills.

\section{ACKNOWLEDGMENTS}

This study is a subproject of a program project "Development of Academic Language in School and at Home (DASH)" coordinated by Paul P. M. Leseman, Utrecht University. The DASH project is funded by The Netherlands Organisation for Scientific Research General Study Grant 411-03-060 and Subproject Grant 411-03-061.

We are grateful to the children and their families who participated in this study. We also acknowledge the student assistants who collected the data: Fatiha Ben Messaoud, Nimet Elmaci, Sema Kiraç, Pinar Okur, Asia Sarti, Judith van der Dool, Judith Verkooijen, and José van Zwieten.

\section{REFERENCES}

Aarts, R., \& Verhoeven, L. (1999). Literacy attainment in a second language submersion context. Applied Psycholinguistics, 20, 377-393.

Backus, A. (2005). Turkish as an immigrant language in Europe. In J. F. Kroll \& A. M. B. De Groot (Eds.), Handbook of bilingualism: Psycholinguistic approaches (pp. 689-723). Oxford: Oxford University Press.

Bialystok, E. (2001). Bilingualism in development: Language, literacy, and cognition. New York: Cambridge University Press.

Bialystok, E. (2007). Cognitive effects of bilingualism: How linguistic experience leads to cognitive change. International Journal of Bilingual Education and Bilingualism, 10, 210-223.

Bialystok, E., \& Senman, L. (2004). Executive processes in appearance-reality tasks: The role of inhibition of attention and symbolic representation. Child Development, 75, 562-579.

Bradley, R. H., \& Caldwell, B. M. (1984). The HOME inventory and family demographics. Developmental Psychology, 20, 315-320.

Bradley, R. H., \& Corwyn, R. F. (2002). Socioeconomic status and child development. Annual Review of Psychology, 53, 371-399.

Butler, Y. G., \& Hakuta, K. (2004). Bilingualism and second language acquisition. In T. Bhatia \& W. C. Ritchie (Eds.), The handbook of bilingualism (pp. 114-144). Malden, MA: Blackwell.

Carver, R. P. (1990). Intelligence and reading ability in grades 2-12. Intelligence, 1, 449-455.

Centraal Bureau voor de Statistiek (CBS). (2001). Standaard Beroepenclassificatie 1992 (SBC 1992), verbeterde editie 2001 [Standard Classification of Occupations 1992, 2001 edition]. Retrieved September 9, 2004, from http://www.cbs.nl/nl-NL/menu/methoden/classificaties/ overzicht/sbc/1992-verbeterde-editie-2001-msi.htm 
Scheele et al.: Home language and language proficiency

Cummins, J. (1991) Interdependence of first- and second-language proficiency in bilingual children. In E. Bialystok (Ed.), Language processing in bilingual children (pp. 70-89). Cambridge: Cambridge University Press.

De Houwer, A. (2007). Parental language input patterns and children's bilingual use. Applied Psycholinguistics, 28, 411-424.

Deckner, D. F., Adamson, L. B., \& Bakeman, R. (2006). Child and maternal contributions to shared reading: Effects on language and literacy development. Applied Developmental Psychology, 27, 31-41.

Duursma, E., Romero-Contreras, S., Szuber, A., Proctor, P., \& Snow, C. E. (2007). The role of home literacy and language environment on bilinguals' English and Spanish vocabulary development. Applied Psycholinguistics, 28, 171-190.

Enders, C. K. (2001). The impact of nonnormality on full information maximum-likelihood estimation for structural equation models with missing data. Psychological Methods, 6, 352-370.

E-Rramdani, Y. (1999). Tweetalige ontwikkeling in context. Het Berbers en het Nederlands van in Nederland wonende kinderen [Bilingual development in context. Berber and Dutch language proficiency of children living in The Netherlands]. Anéla Toegepaste Wetenschap in Artikelen, $61,35-48$.

Field, A. (2005). Discovering statistics using SPSS (2nd ed.). London: Sage Ltd.

Foster, M. A., Lambert, R., Abbott-Shim, M., McCarty, F., \& Franze, S. (2005). A model of home learning environment and social risk factors in relation to children's emergent literacy and social outcomes. Early Childhood Research Quarterly, 20, 13-36.

Genesee, F., Paradis, J., \& Crago, M. B. (2004). Dual language development and disorders: A handbook of bilingualism and second language learning (Vol. 11). Baltimore, MD: Paul H. Brooks.

Gutiérrez-Clellen, V. F., \& Kreiter, J. (2003). Understanding child bilingual acquisition using parent and teacher reports. Applied Psycholinguistics, 24, 267-288.

Hart, B., \& Risley, T. R. (1995). Meaningful differences in the everyday experience of young American children. Baltimore, MD: Paul H. Brookes.

Hoff, E. (2003). The specificity of environmental influence: Socioeconomic status affects early vocabulary development via maternal speech. Child Development, 74, 1368-1378.

Hoff, E. (2006). How social contexts support and shape language development. Developmental Review, $26,55-88$.

Hoff, E., \& Naigles, L. (2002). How children use input to acquire a lexicon. Child Development, 73, 418-433.

Hu, L., \& Bentler, P. M. (1998). Fit indices in covariance structure modeling: Sensitivity to underparameterized model misspecification. Psychological Methods, 3, 424-453.

Huttenlocher, J., Vasilyeva, M., Cymerman, E., \& Levine, S. (2002). Language input and child syntax. Cognitive Psychology, 45, 337-374.

Kaplan, R. M., \& Saccuzzo, D. P. (1997). Psychological testing: Principles, applications, and issues (5th ed.). Pacific Grove, CA: Brooks/Cole.

Kroll, J. F., \& de Groot, A. M. B. (2005). Handbook of bilingualism: Psycholinguistic approaches. New York: Oxford University Press.

Leseman, P. P. M. (2000). Bilingual vocabulary development of Turkish preschoolers in The Netherlands. Journal of Multilingual and Multicultural Development, 21, 93-112.

Leseman, P. P. M., Mayo, A. Y., \& Scheele, A. F. (2009). Old and new media in the lives of young disadvantaged bilingual children. In A. G. Bus \& S. B. Neuman (Eds.), Multimedia and literacy development (pp. 135-155). New York: Routledge.

Leseman, P. P. M., \& Van Den Boom, D. C. (1999). Effects of quantity and quality of home proximal processes on Dutch, Surinamese-Dutch and Turkish-Dutch pre-schoolers' cognitive development. Infant and Child Development, 8, 19-38.

Leseman, P. P. M., \& van Tuijl, C. (2006). Cultural diversity in early literacy: Findings in Dutch studies. In D. Dickinson \& S. Neuman (Eds.), Handbook of early literacy research (Vol. 2, pp. 211-228). New York: Guilford Press.

Linebarger, D. L., \& Walker, D. (2004). Infants' and toddlers' television viewing and language outcomes. American Behavioral Scientist, 48, 624-645.

Messer, M. H., Leseman, P. P. M., Boom, J., \& Mayo, A. Y. (in press). Phonotactic probability effects in nonword recall and its relationship with vocabulary in monolingual and bilingual preschoolers. Journal of Experimental Child Psychology. 
Scheele et al.: Home language and language proficiency

Oller, D. K., \& Eilers, R. E. (2002). Language and literacy in bilingual children. Clevedon: Multilingual Matters.

Oller, D. K., Pearson, B. Z., \& Cobo-Lewis, A. B. (2007). Profile effects in early bilingual language and literacy. Applied Psycholinguistics, 28, 191-230.

Paradis, J., \& Genesee, F. (1995). Language differentiation in early bilingual development. Journal of Child Language, 22, 611-631.

Patterson, J. L. (2002). Relationships of expressive vocabulary to frequency of reading and television experience among bilingual toddlers. Applied Psycholinguistics, 23, 493-508.

Patterson, J. L., \& Pearson, B. Z. (2004). Bilingual lexical development: Influences, contexts, and processes. In B. A. Goldstein (Ed.), Bilingual language development and disorders in SpanishEnglish speakers (pp. 77-104). Baltimore, MD: Paul H. Brookes.

Pearson, B. Z. (2007). Social factors in childhood bilingualism in the United States. Applied Psycholinguistics, 28, 399-410.

Pearson, B. Z., Fernandez, S. C., Lewedeg, V., \& Oller, D. K. (1997). The relation of input factors to lexical learning by bilingual infants. Applied Psycholinguistics, 18, 41-58.

Raven, J. C. (1995). Coloured progressive matrices (CPM). Oxford: Oxford Psychologists.

Raviv, T. K., Kessenich, M., \& Morrison, F. J. (2004). A mediational model of the association between socioeconomic status and three-year-old language abilities: The role of parenting factors. Early Childhood Research Quarterly, 19, 528-547.

Rosenhouse, J., \& Goral, M. (2005). Bilingualism in the Middle East and North Africa: A focus on the Arabic-speaking world. In J. F. Kroll \& A. M. B. De Groot (Eds.), Handbook of bilingualism: Psycholinguistic approaches (pp. 835-859). Oxford: Oxford University Press.

Schön, D., Boyer, M., Moreno, S., Besson, M., Peretz, I., \& Kolinsky, R. (2008). Songs as an aid for language acquisition. Cognition, 106, 975-983.

Sénéchal, M., \& LeFevre, J. (2002). Parental involvement in the development of children's reading skill: A five-year longitudinal study.Child Development, 73, 445-460.

Sociaal en Cultureel Planbureau. (2005). De sociale staat van Nederland [The social state of The Netherlands]. Den Haag, The Netherlands: Author.

Stanat, P., \& Christensen, G. (2006). Where immigrant students succeed: A comparative Review of Performance and Engagement in PISA 2003. Paris: OECD.

Stipek, D. J. (2001). Pathways to constructive lives: The importance of early school success. In A. Bohart \& D. Stipek (Eds.), Constructive and destructive behavior: Implications for family, school, and society (pp. 291-316). Washington, DC: American Psychological Association.

Verhoeven, L. (2007). Early bilingualism, language transfer, and phonological awareness. Applied Psycholinguistics, 28, 425-439.

Verhoeven, L., Narrain, G., Extra, G., Konak, O. A., \& Zerrouk, R. (1995). Diagnostische Toets Tweetaligheid (DTT) [Diagnostic Test of Bilingualism]. Arnhem, The Netherlands: CITO.

Vermeer, A. (1992). Exploring the second language learner lexicon. In J. H. A. L. De Jong \& L. Verhoeven (Eds.), The construct of language proficiency: Applications of psychological models to language assessment (pp. 147-162). Amsterdam: John Benjamins.

Weizman, Z. O., \& Snow, C. E. (2001). Lexical input as related to children's vocabulary acquisition: Effects of sophisticated exposure and support for meaning. Developmental Psychology, 37, 265-279.

Wright, J. C., Huston, A. C., Murphy, K. C., St. Peters, M., Piñon, M., Scantlin, R., et al. (2001). The relations of early television viewing to school readiness and vocabulary of children from low-income families: The early window project. Child Development, 72, 1347-1366. 